\title{
РЕЙДЕРЫ
}

А.А. Спиридонов

DOI: 10.7256/2305-560X.2013.3.8062

\section{ПОЛИТИКО-ПРАВОВЫЕ ОСНОВЫ ПРОТИВОДЕЙСТВИЯ РЕЙДЕРСКИМ ЗАХВАТАМ}

\begin{abstract}
Аннотация. Рейдерство в современной России продолжсает оставаться одной из основных экономико-правовых проблем. Однако уже более двадцати лет не существует единой антирейдерской политики, отсутствует понятная и работающая законодательная база. В связи с этим перед исследователями стоит задача определения вектора противостояния рейдерским захватам на законодательном уровне. Ситуация также имеет и политическое расширение, т.к. существует ряд групп интересов, ставящих целью консервацию ситуации. Сама проблема рейдерства в свою очередь приобретает статус угрозы национальной безопасности. По мнению автора, первостепенной задачей в борьбе с рейдерством должна стать его классификация как отдельного преступления в Уголовном кодексе РФ.
\end{abstract}

Ключевые слова: политология, рейдерство, закон, безопасность, антирейдерство, предпринимательство, гринмейл, мошенничество, преступление, законотворчество.

$\mathrm{B}$ современных СМИ проблема рейдерства отошла на второй план: отгремел «беспредел» девяностых и прошли рейдерские войны первого десятилетия нынешнего века. Однако проблема рейдерства не уходит из современной повестки дня. Как волны, рейдерские захваты проносятся по экономической поверхности Российской Федерации. С каждым изменением в любом из имущественных кодексов у рейдеров появляется все больше и больше возможностей для недружественного слияния и поглощения. Для простого обывателя само слово рейдерство, как правило, ассоциируется со словами «рекет» или «грабеж», тогда как для академической среды проблемы рейдерства словно не существует: кафедры экономических ВУЗов обходят эту проблему как «неэкономическую», в то же время ученые-юристы закрывают глаза на прямую связь между неточностями (а иногда и преступными ошибками) в законах и возможностью рейдерских захватов. Политическая наука не уделяет особого внимания данным вопросам, относя проблему рейдерства либо к экономической, либо к юридической сфере, забывая о том, что для любого рейдерского захвата связи с органами власти и процессы законотворчества крайне важны ${ }^{1}$. Так, на сайте Комитета по экономическому развитию, промышленной политике и торговли Санкт-Петербурга рейдейство обозначается как проблема сознательного

\footnotetext{
1 Федоров А.Ю. Рейдерство и корпоративный шантаж:(орг.правовые меры противодействия). Wolters Kluwer Russia, 2010. C. 36-38.
}

раздувания рейдерами социальной розни и поднимается вопрос о недооценке неприязни большинством населения практики частного предпринимательства. Проблема рейдерства в конечном итоге выносится автором на уровень PR-служб, которые «должны поменять имидж рейдеров». Подобным образом акцент ставится на отсутствие сформированной позиции гражданского общества, а не на экономический и политический урон, который причиняет рейдерство ${ }^{2}$.

Так что же такое рейдерство? Как выделить в отдельную сферу область недружественных слияний и поглощений в реалиях России? Ответ на этот вопрос зачастую дается уклончивый. Для кого-то рейдерство это в первую очередь гринмейл, корпоративный шантаж, другие видят рейдерство там, где имеет место обычное вымогательство ${ }^{4}$. В рамках данной статьи мы склонны придерживаться следующего определения данного термина: рейдерство есть недружественное поглощение предприятия (юридического лица) против воли его собственников, имеющих преимущественное положение в данном предприятии, либо его руково-

\footnotetext{
2 «Рейдерство - это преступление»// Комитет экономического развития, промышленной политики и торговли. [электронный ресурс] // URL:http://www.spb-mb.ru/index. php?page=154 (дата доступа 30.03.2013).

3 Нехорошев Ю.С., Таран Е.А. Анатомия российского рейдерства // Известия Томского политехнического университета. 2009. C. 21

4 Агламзянов А.С. Рейдерство в России //Молодые ученые в решении актуальных проблем науки. 2009. С. 158.
} 
дителя. Данное определение является достаточно строгим, чтобы исключить из области внимания корпоративный шантаж и формы борьбы внутри фирмы (административная игра, «подсиживание» и т.д.). Одновременно с этим именно такое определение указывает на проблемы, которые создает рейдерство. Любая более расплывчатая формулировка позволяет нивелировать данную проблему уже на стадии законотворчества, «размывая» само преступление определениями из других, зачастую сопутствующих деяний противоправного характера (подлог, подкуп, мошенничество).

Какие проблемы создает рейдерство в современной России, почему вообще возможно, присваивать чужие юридические лица и имущество, к ним приписанное, против воли их владельцев? Ответ на это лежит в самом вопросе: отсутствует какая-либо четкая законодательная база, позволяющая привлекать к ответственности не рядовых исполнителей, а заказчиков рейдерских захватов ${ }^{5}$. Исполнение самого рейдерского захвата сопряжено с множеством противоправных действий: преступлениями против личности различного характера, подлогом документов и многими другими действиями, подпадающими под УК РФ ${ }^{6}$. Из поля зрения современных законодателей уходит антиличностный, антисоциальный и антигосударственный характеры недружественного поглощения: зачастую параллельно с процессом недружественного поглощения совершаются общественно опасные преступления, нередко объектами рейдерских захватов выступают предприятия или фонды государственной значимости, но этот процесс не всегда воспринимается как преступный. Наказываются, как правило, обычные исполнители, а не заказчики или идейные вдохновители данных преступлений․ Тактика рейдерских захватов - популярная мера экономической борьбы западных спецслужб, однако корни многих из нашумевших рейдерских захватов даже не пытаются увязывать с возможным влиянием зарубежных агентур. Однако в этом направлении есть определенные подвижки. По данным российских спецслужб, рейдеры наце-

\footnotetext{
5 Мирина Н.В. Правовые тенденции развития российского законодательства в области противодействия рейдерским атакам // Вестник Волгоградского государственного университета. 2011. №. 2. С. 120-121.

6 Брагин И.А. Содержательные компоненты рейдерства: криминологическая характеристика и классификация // Вестник Челябинского государственного университета. 2013. №. 5. C. 296.

7 Щепилов О.О. Преступления в сфере недружественных поглощений: понятие и виды// Вестник Следственного комитета при прокуратуре Российской Федерации. № 3 (5). 2009. С. 18.
}

лились на захват более 200 российских оборонных предприятий. Эту цифру Павел Астахов, пишет «Газета»: «Чувствуя свою безнаказанность, захватчики обратили внимание на госсобственность - научнопроизводственное предприятие «Базальт», которое производит лучшие в мире гранатометы, объекты Минобороны в Поволжье (военный санаторий «Волга», дворец спорта ЦСКА ВВС, Самарский загородный парк, более 200 других объектов муниципальной собственности), речные порты и заводы оборонного назначения «ЭнергоПУЛ» и «Рефлектор» в Саратове, завод, выпускающий компоненты для переносных ракет «Игла» в Санкт-Петербурге» ${ }^{8}$.

Законодатели, как и в девяностые годы, склонны списывать эту проблему на незрелость демократии и рынка. Во многом рынок в современной России имеет черты, похожие на дикий капитализм, и это вовсе не значит, что необходимо оставлять в его в таком состоянии. Именно решение проблемы рейдерства возможно качественно изменить рыночную, следовательно и экономическую ситуацию в России в лучшую сторону. Ситуация не меняется с середины первого десятелетия XXI в.: в статьях посвященных одной и первых инициатив «антирейдерского закона» угадывается тот же скептицизм, что и в последующих 9 . Меры, на которые идут законодатели явно малоэффективны, направлены в первую очередь на создание новых пространств для рейдерских захватов или ненамеренно ведут к возникновению паразитических структур, вытягивающих ресурсы из бизнеса. Законодательные поправки как нынешних, так и прошлых законодателей способны только сокращать число рейдеров-непрофессионалов, лиц, незнакомых со всеми тонкостями недружественных поглощений. Однако пока представители народа продолжают принимать все новые и новые законы, открывающие простор для рейдерских захватов, число новых участников рейдерского сообщества не пойдет на

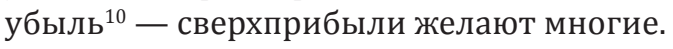

\footnotetext{
8 По данным российских спецслужб, рейдеры нацелились на захват более 200 российских оборонных предприятий // Информационное агентство «Оружие России» - [электронный ресурс] URL:http://www.arms-expo.ru/049057054050124049057050052. html (дата доступа 30.03.2013).

9 Рейдеры: как бороться. // Тамбовская областная торговопромышленная палата. - [Электронный ресурc] URL:http:// www.totpp.ru/business-tambov/archive/dec-2007/491-article9 (дата доступа 30.03.2013).

10 Кривенко П.А. Инновации, рейдерство и институты в стране, обеспеченной природными ресурсами. «Научные доклады лаборатории макроэкономического анализа». М.: Изд. дом Государственного университета - Высшей школы экономики, № 05, 2009. С. 1-52.
} 


\section{Международные отношения International Relations}

Однако почему антирейдерский закон ещё не принят, почему рейдерство все ещё остается бичом современной России? Для этого есть несколько причин. Первая причина - это имущественный раскол населения РФ. Большая часть населения России не обладает возможностью начать собственное дело ${ }^{11}$ и опытом подобных дел. Коэффициент Джини для России уже с середины 1990-х принял критические значения и продолжает увеличиваться. Средства, что требуются для входа на рынок и создания собственного дела, подчас недоступны российскому обывателю ${ }^{12}$. Сохраняется советская и перестроечная инерция, которая вызывает в людях чувство отторжения к таким категориям как «частное предпринимательство», «фирма», «корпорация» ${ }^{13}$. Подавляющее большинство россиян - от $65 \%$ до $\mathbf{8 0} \%$ - негативно относятся как к предпринимателям, так и к предпринимательству как явлению ${ }^{14}$. Причина лежит на поверхности - свыше 70\% сограждан считают, что «в России нельзя заработать деньги законно», эти цифры были приведены на последнем заседании Никитского клуба (под президентством профессора Сергея Капицы), который объединяет группу известных предпринимателей и ученых). Вторая причина - это криминальная идеология, закрепившаяся в сознании граждан, что делает антирейдерские меры «непонятными усложнениями» для рядового жителя ${ }^{15}$. Третья причина - это ничтожно малое количество и низкое качество антирейдерских организаций, неструктурированность антирейдерских услуг рынка (многие даже не догадываются, что могут найтись люди, более компетентные в данных вопросах, чем юри-

11 Путин В.В. Выступление на расширенном заседании Государственного совета «О стратегии развития России до 2020 года». М.: Европа. 2008. С. 12.

12 Гонтмахер Е.Ш. Экспертное мнение по проблеме неравенства в России в соответствии с темами,

отраженными в отчёте Оксфам «Забытые «Большой Двадцаткой»? // Оксфам в России. - [электронный ресурс]//URL: http:// www.oxfamblogs.org/russia/wp-content/uploads/2012/04/\%D0 $\%$ AD $\%$ D0 $\%$ BA $\%$ D $1 \% 81 \%$ D0 $\%$ BF $\%$ D0 $\%$ B5\%D $1 \% 80 \% \mathrm{D} 1-$ $\% 82 \% \mathrm{D} 0 \% \mathrm{BD} \% \mathrm{D} 0 \% \mathrm{BE} \% \mathrm{D} 0 \% \mathrm{~B} 5-\% \mathrm{D} 0 \% \mathrm{BC} \% \mathrm{D} 0 \% \mathrm{BD} \% \mathrm{D} 0$ $\% \mathrm{~B} 5 \% \mathrm{D} 0 \% \mathrm{BD} \% \mathrm{D} 0 \% \mathrm{~B} 8 \% \mathrm{D} 0 \% \mathrm{~B} 5 .-\mathrm{0D} 0 \% 93 \% \mathrm{D} 0 \% \mathrm{BE} \% \mathrm{D} 0 \%$ BD $\%$ D $1 \% 82 \% \mathrm{D} 0 \% \mathrm{BC} \% \mathrm{D} 0 \% \mathrm{~B} 0 \% \mathrm{D} 1 \% 85 \% \mathrm{D} 0 \% \mathrm{~B} 5 \% \mathrm{D} 1 \% 80-$ $\% \mathrm{D} 0 \% 95 . \% \mathrm{D} 0 \% \mathrm{~A} 8 . . p d f$ (дата доступа 30.03.2013).

13 Зудин А.Ю. Общественная легитимация частного предпринимательства в России // Мировая экономика и международные отношения. 2000. № 011. С. 65-74.

14 Лапкин В.В., Пантин В.И. Русский порядок // Полис. 1997. T. 3. C. 74-88.

15 Кочетков А. Воздействие криминальной идеологии на культуру России // Законность. 2001. №. 10. С. 40-43. дические отделы фирм $)^{16}$. Также существует четвертая, теневая и наиболее замалчиваемая причина: прорейдерское лобби в законодательных органах РФ. Именно оно во многом акцентирует внимание на изменении имущественных кодексов, искажает идеи антирейдерских законов и во многом продвигает идеи холдингов, не брезгующих рейдерскими захватами.

Пути решения данной проблемы крайне разнообразны. Повышение качества антирейдерских услуг, появление на рынке противорейдерских фирм с «белым», чистым прошлым способно серьезно оздоровить ситуацию. В свою очередь, осознание российскими законодателями всей серьезности данной проблемы позволит перейти на качественно иной уровень нормативной базы экономической деятельности. Перед нами открывается также и глобальное расширение данной проблемы: без практик частного и честного мелкого предпринимательства (коим сильно препятствуют этнические и административные и прочие сложности), невозможно поддерживать ни антирейдеров с чистой репутацией, ни нормальное функционирование законов, направленных против рейдеров.

Вполне возможно, что одним из основных и первостепенных шагов для решения этой проблемы является введение закона, в котором четко и ясно будут обозначены категории рейдерства и будет подчеркнута общественная и государственная опасность подобного рода преступлений. Пробная формулировка данного закона приведена ниже.

\section{Диспозищия/санкция:}

1. Рейдерство, то есть организация недружественного поглощения предприятия против воли его собственников имеющих преимущественное положение в данном предприятии, либо его руководителя.

Наказывается принудительными работами на срок от двух до четырех лет и штрафом в размере 600 MPOT

2. Рейдерство:

1. Совершенное лищом, находящимся на государственной службе

2. Совершенное группой лии, группой лиц по предварительному сговору или организованной группой

3. Сопряженное с мошенничеством, подлогом документов, подкупом

16 Новиков П.С. Причины неэффективности мер по противодействию «рейдерству» в период с 2002 по 2009 гг. - Вестник МГОУ. Серия «Юриспруденция». № 3, 2011. С. 74-78. 
Наказывается лишением свободы на срок от четырех до шести лет и штрафом в размере 1200 MPOT

3. Рейдерство:

1. Сопряженное с убийством

2. Сопряженное с экоцидом

3. Совершенное общеопасным способом

4. Сопряженное с бандитизмом
Наказывается лишением свободы от пяти до 15 лет и штрафбом в размере от 2000 до 6000 МРОТ

4. Рейдерство:

1. Сопряженное с нарушением государственной тайны

2. Сопряженное с государственной изменой

Наказывается лишением свободы от 10 до 20 лет и шттрафом в размере 4000 до 12000 МРОТ .

\section{Источники:}

1. Агламзянов А.С. Рейдерство в России // Молодые ученые в решении актуальных проблем науки, 2009. C. $158-162$.

2. Брагин И.А. Содержательные компоненты рейдерства: криминологическая характеристика и классификация // Вестник Челябинского государственного университета. - 2013. - №. 5 (296). - С. 61-70.

3. Зудин А.Ю. Общественная легитимация частного предпринимательства в России // Мировая экономика и международные отношения. - 2000. — № 011. — С. 65-74.

4. Кочетков А. Воздействие криминальной идеологии на культуру России // Законность. - 2001. № 10. - С. 40-43.

5. Кривенко П.А. Инновации, рейдерство и институты в стране, обеспеченной природными ресурсами. «Научные доклады лаборатории макроэкономического анализа». - М.: Изд. дом Государственного университета - Высшей школы экономики, № 05, 2009. - 52 с.

6. Лапкин В.В., Пантин В.И. Русский порядок // Полис. - 1997. Т. 3. - С. 74-88.

7. Мирина Н.В. Правовые тенденции развития российского законодательства в области противодействия рейдерским атакам // Вестник Волгоградского государственного университета. - 2011. - №. 2. C. $120-121$.

8. Нехорошев Ю.С., Таран Е.А. Анатомия российского рейдерства // Известия Томского политехнического университета. - 2009. - С. 20-23.

9. Новиков П.С. Причины неэффективности мер по противодействию «рейдерству» в период с 2002 по 2009 гг. - Вестник МГОУ. Серия «Юриспруденция». — № 3, 2011 — С. 74-78.

10. Путин В.В. Выступление на расширенном заседании Государственного совета «0 стратегии развития России до 2020 г.». - М.: Европа, 2008. - 17 с.

11. Федоров А.Ю. Рейдерство и корпоративный шантаж: (орг.-правовые меры противодействия). - Wolters Kluwer Russia, 2010. - 468 c.

12. Щепилов 0.0. Преступления в сфере недружественных поглощений: понятие и виды// Вестник Следственного комитета при прокуратуре Российской Федерации. — № 3 (5). - 2009. - С. 17-21.

13. «Рейдерство - это преступление» // Комитет экономического развития, промышленной политики и торговли. - [электронный ресурс] // URL:http://www.spb-mb.ru/index.php?page=154 (дата доступа 30.03.2013).

14. Гонтмахер Е.Ш. Экспертное мнение по проблеме неравенства в России в соответствии с темами, отраженными в отчёте Оксфам «Забытые «Большой Двадцаткой»? // Оксфам в России. — [электронный ресурс] // URL: http://www.oxfamblogs.org/russia/wp-content/uploads/2012/04/\%D0\%AD\%D0\%BA\%D1\%8 1\%D0\%BF\%D0\%B5\%D1\%80\%D1\%82\%D0\%BD\%D0\%BE\%D0\%B5-\%D0\%BC\%D0\%BD\%D0\%B5\%D0\%BD \%D0\%B8\%D0\%B5.-\%D0\%93\%D0\%BE\%D0\%BD\%D1\%82\%D0\%BC\%D0\%B0\%D1\%85\%D0\%B5\%D1\%80\%D0\%95.\%D0\%A8..pdf (дата доступа 30.03.2013).

15. По данным российских спецслужб, рейдеры нацелились на захват более 200 российских оборонных предприятий // Информационное агентство «Оружие России». - [электронный ресурс] // URL:http:// www.arms-expo.ru/049057054050124049057050052.html (дата доступа 30.03.2013).

16. Рейдеры: как бороться. // Тамбовская областная торгово-промышленная палата. - [Электронный pecypc] // URL:http://www.totpp.ru/business-tambov/archive/dec-2007/491-article9 (дата доступа 30.03.2013). 


\section{Международные отношения International Relations}

\section{References (transliteration):}

1. Aglamzyanov A.S. Reiderstvo v Rossii // Molodye uchenye v reshenii aktual'nyh problem nauki, 2009. — S. 158-162.

2. Bragin I.A. Soderzhatel'nye komponenty reiderstva: kriminologicheskaya harakteristika i klassifikaciya // Vestnik Chelyabinskogo gosudarstvennogo universiteta. — 2013. — №. 5 (296). — S. 61-70.

3. Zudin A.Yu. Obshestvennaya legitimaciya chastnogo predprinimatel'stva v Rossii // Mirovaya ekonomika i mezhdunarodnye otnosheniya. — 2000. — № 011. - S. 65-74.

4. Kochetkov A. Vozdeistvie kriminal'noi ideologii na kul'turu Rossii // Zakonnost'. — 2001. — № 10. — S. 40-43.

5. Krivenko P.A. Innovacii, reiderstvo i instituty v strane, obespechennoi prirodnymi resursami. "Nauchnye doklady laboratorii makroekonomicheskogo analiza". - M.: Izd. dom Gosudarstvennogo universiteta - Vysshei shkoly ekonomiki. № 05, 2009. — 52 s.

6. Lapkin V.V., Pantin V.I. Russkii poryadok // Polis. - 1997. T. 3. - S. 74-88.

7. Mirina N.V. Pravovye tendencii razvitiya rossiiskogo zakonodatel'stva $v$ oblasti protivodeistviya reiderskim atakam // Vestnik Volgogradskogo gosudarstvennogo universiteta. — 2011. — № 2. — S. 120-121.

8. Nehoroshev Yu.S., Taran E.A. Anatomiya rossiiskogo reiderstva // Izvestiya Tomskogo politehnicheskogo universiteta. - 2009. - S. 20-23.

9. Novikov P.S. Prichiny neeffektivnosti mer po protivodeistviyu «reiderstvu»v period s 2002 po 2009 gg. — Vestnik MGOU. Seriya «Yurisprudenciya». — № 3, 2011. — S. 74-78.

10. Putin V.V. Vystuplenie na rasshirennom zasedanii Gosudarstvennogo soveta «O strategii razvitiya Rossii do 2020 goda». - M.: Evropa. - 2008. - $17 \mathrm{~s}$.

11. Fedorov A.Yu. Reiderstvo i korporativnyi shantazh: (org.-pravovye mery protivodeistviya). - Wolters Kluwer Russia, 2010. - $468 \mathrm{~s}$.

12. Shepilov 0.0. Prestupleniya v sfere nedruzhestvennyh pogloshenii: ponyatie i vidy// Vestnik Sledstvennogo komiteta pri prokurature Rossiiskoi Federacii. — № 3 (5). — 2009. — S. 17-21.

13. «Reiderstvo - eto prestuplenie» // Komitet ekonomicheskogo razvitiya, promyshlennoi politiki i torgovli. [elektronnyi resurs] // URL:http://www.spb-mb.ru/index.php?page=154 (data dostupa 30.03.2013).

14. Gontmaher E.Sh. Ekspertnoe mnenie po probleme neravenstva v Rossii v sootvetstvii s temami, otrazhennymi $v$ otchete Oksfam «Zabytye «Bol'shoi Dvadcatkoi»? // Oksfam v Rossii. — [elektronnyi resurs] // URL: http://www. oxfamblogs.org/russia/wp-content/uploads/2012/04/\%D0\%AD\%D0\%BA\%D1\%81\%D0\%BF\%D0\%B5\%D1 \%80\%D1\%82\%D0\%BD\%D0\%BE\%D0\%B5-\%D0\%BC\%D0\%BD\%D0\%B5\%D0\%BD\%D0\%B8\%D0\%B5.-\%D 0\%93\%D0\%BE\%D0\%BD\%D1\%82\%D0\%BC\%D0\%B0\%D1\%85\%D0\%B5\%D1\%80-\%D0\%95.\%D0\%A8..pdf (data dostupa 30.03.2013).

15. Po dannym rossiiskih specsluzhb, reidery nacelilis' na zahvat bolee 200 rossiiskih oboronnyh predpriyatii // Informacionnoe agentstvo «Oruzhie Rossii». — [elektronnyi resurs] // URL:http://www.arms-expo. ru/049057054050124049057050052.html (data dostupa 30.03.2013).

16. Reidery: kak borot'sya // Tambovskaya oblastnaya torgovo-promyshlennaya palata. — [Elektronnyi resurs] // URL:http://www.totpp.ru/business-tambov/archive/dec-2007/491-article9 (data dostupa 30.03.2013). 